\title{
Effectiveness of the MetSLIM lifestyle intervention targeting individuals of low socio-economic status and different ethnic origins with elevated waist-to-height ratio
}

\author{
Andrea J Bukman ${ }^{1} \dagger$, Dorit Teuscher ${ }^{2} \dagger$, Agnes Meershoek ${ }^{3}$, Reint Jan Renes ${ }^{4}$, \\ Marleen A van Baak ${ }^{2}$ and Edith JM Feskens ${ }^{1, *}$ \\ 'Wageningen University, Division of Human Nutrition, PO Box 17, 6700 AA Wageningen, The Netherlands: \\ ${ }^{2}$ Maastricht University Medical Centre +, NUTRIM School for Nutrition and Translational Research in Metabolism, \\ Department of Human Biology and Movement Sciences, Maastricht, The Netherlands: ${ }^{3}$ Maastricht University \\ Medical Centre +, CAPHRI, Department of Health, Ethics and Society, Maastricht, The Netherlands: ${ }^{4}$ Wageningen \\ University, Division of Strategic Communication, Wageningen, The Netherlands
}

Submitted 31 December 2016: Final revision received 18 May 2017: Accepted 30 May 2017: First published online 24 July 2017

\begin{abstract}
Objective: To evaluate whether the lifestyle intervention MetSLIM targeting individuals of low socio-economic status of Turkish, Moroccan and Dutch origin was successful in improving waist circumference and other cardiometabolic risk factors, lifestyle behaviour and quality of life.

Design: A quasi-experimental intervention study (Netherlands Trial Register NTR3721). The intervention group participated in a 12-month combined dietary and physical activity programme. Examinations were performed at baseline and after 12 months. Participants underwent anthropometric measurements and blood withdrawal, and completed questionnaires on dietary intake, physical activity and quality of life.

Setting: Socio-economically deprived neighbourhoods in two Dutch cities, involving non-blinded ethnicity-matched and gender-matched research assistants, dietitians and sports instructors.

Subjects: Mainly Turkish (49\%) and Dutch (36\%) subjects, aged 30-70 years, with a waist-to-height ratio of $>0 \cdot 5$ (intervention, $n 117$; control, $n 103$ ). Dropout was $31 \%$. Results: At 12 months, the intervention group showed greater improvements than the control group in waist circumference $(\beta=-3.3 \mathrm{~cm}, 95 \% \mathrm{CI}-4.7,-1 \cdot 8$, $P<0.001)$ and other obesity measures. Additionally, greater reductions were observed for total cholesterol $(\beta=-0.33 \mathrm{mmol} / 1,95 \% \mathrm{CI}-0 \cdot 56,-0 \cdot 10, P=0 \cdot 005)$ and LDL cholesterol $(\beta=-0.35 \mathrm{mmol} / 1,95 \% \mathrm{CI}-0.56,-0 \cdot 14, P=0 \cdot 001)$. Dietary changes were significant for fibre intake $(\beta=1 \cdot 5 \mathrm{~g} / 4184 \mathrm{~kJ}(1000 \mathrm{kcal}), 95 \% \mathrm{CI} 0 \cdot 3$, $2 \cdot 7, P=0 \cdot 016)$. Compared with the control group, the intervention group reported a decrease in total minutes of physical activity $(\beta=-573 \mathrm{~min} /$ week, $95 \% \mathrm{CI}-1126$, $-21, P=0.042)$ and showed improvements in the quality-of-life domains 'health transition' and 'general health'.

Conclusions: MetSLIM was shown to be effective in improving waist circumference, total and LDL cholesterol, and quality of life among Dutch and Turkish individuals living in deprived neighbourhoods.
\end{abstract}

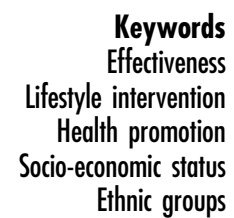

Keywords

intervention

Health promotion

Ethnic groups
Lifestyle intervention studies such as the Diabetes Prevention Program (DPP) and the Diabetes Prevention Study have shown that lifestyle interventions have beneficial effects on risk factors for cardiometabolic diseases and reduce the development of type 2 diabetes mellitus ${ }^{(1-3)}$. The success of these studies has led to the adaptation of

$\dagger$ These authors contributed equally to this work. these lifestyle interventions towards several different target groups and settings ${ }^{(4-9)}$.

In the Netherlands, the Study of Lifestyle intervention and Impaired glucose tolerance Maastricht (SLIM) also showed that a combined diet and physical activity intervention reduces diabetes risk ${ }^{(10)}$. The SLIM study was a randomised controlled trial studying the effectiveness of a lifestyle intervention on glucose tolerance in persons with impaired 
glucose tolerance. Participants in the lifestyle intervention received $1 \mathrm{~h}$ of individual dietary advice every 3 months and one group session per year, lasting $90 \mathrm{~min}$, led by a dietitian. In addition, they could participate in a weekly supervised aerobic and resistance training programme at the university fitness centre ${ }^{(11)}$. In that trial, individuals with low socio-economic status (SES) were more likely to drop out than individuals with higher $\mathrm{SES}^{(12)}$. This is unfortunate, as in general the prevalence of CVD and type 2 diabetes mellitus is relatively high among individuals with low $\mathrm{SES}^{(13)}$. Others have also shown that this group is less likely to participate in lifestyle interventions and more likely to drop out early ${ }^{(14-16)}$. Similar patterns, with respect to both the higher prevalence of cardiometabolic diseases and the high dropout rates, have been observed in ethnic minorities living in the Netherlands ${ }^{(17-20)}$. Therefore, this group forms an important target group for lifestyle interventions.

In order to tackle the under-representation of socioeconomically disadvantaged individuals and ethnic minorities in health promotion activities, adapted methods are necessary to reach and retain this group effectively $^{(21-23)}$. For this reason, we adapted the SLIM study to the needs and preferences of low-SES individuals of Dutch, Turkish and Moroccan origin (the three largest ethnic groups in the Netherlands) based on the findings of preceding research ${ }^{(22,24,25)}$. This adapted study was named MetSLIM.

Following the preferences of the target group, adaptations included additional group meetings about topics relevant for the target group; involving ethnicity- and gender-matched research assistants, dietitians and sports instructors; activities provided for women and men separately; and all activities provided in participants' own neighbourhood. Study design, setting and measurements were chosen to minimise the burden of participation. A detailed overview of the choices and considerations in the adaptation process from SLIM to MetSLIM is described elsewhere $^{(25)}$. The aim of the present study was to evaluate whether the adapted lifestyle intervention was successful in improving waist circumference and other cardiometabolic risk factors, lifestyle behaviour and quality of life among low-SES individuals of Dutch, Turkish and Moroccan origin.

\section{Methods}

\section{Study design}

MetSLIM was a quasi-experimental study running from January 2013 until June 2015 in two cities in the Netherlands. Participants were invited to either the intervention group or the control group. Measurements were not taken blinded; researchers knew which group the participants belonged to. Participants were blinded to the study design; participants knew that the effect of the programme was being evaluated, however, they were not aware of the existence of a comparison group receiving a different programme. All participants gave their written informed consent before the start of the study. The design of the MetSLIM study has been published in more detail previously $^{(25)}$.

\section{Recruitment}

Individuals of Dutch, Turkish and Moroccan origin, aged 30-70 years, were recruited in socio-economically deprived neighbourhoods. Intervention group participants were recruited in different neighbourhoods from control group participants to avoid dissatisfaction and spill-over. The aim was to achieve similar numbers of participants for each ethnicity (frequency matching) in the intervention and control groups. Two recruitment strategies were used. First, participants were recruited via general practices that either were situated in socioeconomically deprived neighbourhoods or had a broad spectrum of low-SES patients or ethnic minority patients. General practitioners made a selection of potential participants in their database based on the inclusion criteria that were available in their registry, such as age, medication use and postal code (as an indicator for neighbourhood). General practitioners were asked to select only patients from Dutch, Turkish and Moroccan origin who were physically and mentally able to participate in the intervention. Second, participants were recruited in community centres involving community health workers (e.g. social workers), local health professionals and other local contacts. Interested persons were asked to fill out a screening questionnaire to check whether they fulfilled the inclusion or the exclusion criteria.

The inclusion criteria were: (i) waist-to-height ratio (WHtR) >0.5; (ii) aged between 30 and 70 years; (iii) no medication for hypertension, hypercholesterolaemia, CVD, diabetes mellitus or/and renal failure at baseline; (iv) living in a socio-economically deprived neighbourhood; and (v) Dutch, Turkish or Moroccan ethnic origin. Following the definitions of Statistics Netherlands, persons with both parents born in the Netherlands are considered to be Dutch ${ }^{(26)}$ and persons who have at least one parent born in Morocco/Turkey are considered to be Moroccan/ Turkish ${ }^{(27)}$. However, if persons signed up for the study from neighbourhoods close by or of another ethnic background, they were also accepted for participation in the study as it was considered unethical and undesirable (for social cohesion) to exclude them. Exclusion criteria were: (i) having a mental or physical disability that made participation in a lifestyle intervention impossible; (ii) already participating in a lifestyle programme targeting weight loss; and (iii) pregnant or lactating.

Based on the results of the screening questionnaire, eligible participants were invited for baseline measurements. The appointment for baseline measurements took place at a community or health-care centre in participants' own neighbourhood. At the beginning of this appointment, 
participants gave written informed consent. At the end of the appointment, participants received a referral letter to the medical laboratory for blood withdrawal and instructions for the start of the intervention or control programme. During the inclusion period (January 2013 to June 2014), 220 participants with elevated WHtR enrolled in the study, of whom 117 participated in the intervention group and 103 in the control group.

\section{Intervention and control groups}

The intervention group participated in a 12-month lifestyle intervention that promoted lifestyle change and weight loss through increased physical activity and changes in dietary habits following the general Dutch public health recommendations ${ }^{(28)}$ (see the online supplementary material, Supplemental File 1). The lifestyle intervention was provided in a community setting and consisted of three components: four group meetings, $4 \mathrm{~h}$ of individual dietary advice and weekly sports lessons. All group meetings on nutrition were provided separately for Dutch, Turkish and Moroccan participants. The individual dietary advice (maximum $4 \mathrm{~h}$ ) was divided over a flexible number of consultations and was given by a dietitian who was ethnicity-matched to the Dutch, Turkish and Moroccan participants. Dietitians tailored their advice, based on the national guidelines on healthy nutrition ${ }^{(28)}$, to the needs of each participant. Additionally, participants were invited to join the four group meetings $(90 \mathrm{~min})$. The first was an introductory meeting, guided by the researcher, in which participants got to know the dietitian, the sports instructor and other study participants. The other three group meetings were about nutrition and were guided by the dietitian. The group meeting focused on label reading, social occasions and price concerns (supermarket tour). Because of a lack of interest or other thematic priorities, the meeting on price concerns was in some cases replaced by a meeting about 'Staying motivated' or 'Ramadan'. The dietary advice and the group meetings were, if preferred, given in participants' native language. The physical activity lessons $(60 \mathrm{~min})$ were set up especially for the study participants and were tailored to the needs and preferences of the sports groups. Sports instructors provided a variety of activities such as basketball, circuit training, core stability, zumba and walking. The physical activity classes for ethnicities other than Dutch were provided separately for women and men with gender-matched sports instructors. Participants were allowed to bring friends and family along to the physical activity lessons if that was feasible given the space of the physical activity location.

The participants in the control group received only one group meeting $(90 \mathrm{~min}$ ) guided by a dietitian, together with, if necessary, a language assistant with a dietetic background. The dietitian provided the group with general information about a healthy diet. Additionally, participants received information leaflets on the benefits of healthy nutrition and increased physical activity.
The intervention programme was promoted as 'TogetherLongerHealthy' and the control programme as 'Health check'. Both groups participated in the same measurements. All participants received the results of their own measurements. Measurement results were also sent to the general practitioners.

\section{Outcome measures}

To evaluate the effectiveness of the lifestyle intervention programme, data were collected at baseline and after 12 months. Participants underwent physical examinations and were asked to fill in questionnaires, either alone or together with a research assistant speaking their native language. Standardised measurement procedures were followed, which were described in protocols. Height was measured without shoes to the nearest millimetre. Body weight and body fat percentage were measured with a Tanita BC-418 bioimpedance scale (Tanita Corporation, Tokyo, Japan). Waist circumference was determined midway between the lowest rib and the iliac crest, and hip circumference was measured at the widest portion of the buttocks. Both were measured twice to the nearest $0.5 \mathrm{~cm}$ and averaged. Blood pressure was measured six times (with $2 \mathrm{~min}$ of rest in between) in a seated position with an Omron 705CP (Omron Healthcare Co., Kyoto, Japan). The mean was calculated from the last five measurements. Blood samples were taken after at least $10 \mathrm{~h}$ of fasting to measure fasting glucose, HDL cholesterol, total cholesterol, TAG, HbA1c (glycated $\mathrm{Hb}$ ), fasting insulin, liver function enzymes, creatinine and uric acid. A fasting spot urine sample was collected to measure albumin and creatinine. Analyses were performed at either SHO laboratory in Velp or Maxima Medisch Centrum laboratory in Veldhoven, the Netherlands, depending on the location of the blood sampling. For fasting insulin, all blood samples were analysed at SHO laboratory in Velp.

Albuminuria was determined by the ratio between urinary concentrations of albumin and creatinine, with a cut-off of $>2.5 \mathrm{mg} / \mathrm{mmol}$ for men and $>3.5 \mathrm{mg} / \mathrm{mmol}$ for women ${ }^{(29)}$. LDL cholesterol was calculated using the Friedewald formula ${ }^{(30)}$. Metabolic syndrome was defined by the revised National Cholesterol Education Program Adult Treatment Panel III criteria as the presence of three or more of the following five cardiometabolic risk factors: (i) increased waist circumference (men $\geq 102 \mathrm{~cm}$, women $\geq 88 \mathrm{~cm}$ ); (ii) low HDL cholesterol (men $<1.03 \mathrm{mmol} / 1$, women $<1.29 \mathrm{mmol} / 1$ or on drug treatment for reduced HDL cholesterol); (iii) high TAG level ( $\geq 1.69 \mathrm{mmol} / 1$ or on drug treatment for elevated TAG); (iv) increased blood pressure (systolic $\geq 130 \mathrm{mmHg}$ and/or diastolic $\geq 85 \mathrm{mmHg}$ or on antihypertensive drug treatment); and (v) impaired fasting glucose $(\geq 5.6 \mathrm{mmol} / \mathrm{l}$ or on drug treatment for elevated glucose $)^{(31)}$. For participants with both parents born in Asia (except for countries in the Middle East), cutoff values of $90 \mathrm{~cm}$ (men) and $80 \mathrm{~cm}$ (women) for waist circumference were used ${ }^{(31)}$. 
Physical activity was measured with the Short Questionnaire to Assess Health-enhancing physical activity (SQUASH) ${ }^{(32)}$. Dietary intake was assessed with ethnicspecific FFQ ${ }^{(33)}$ and calculated using the 2013 Dutch food composition database ${ }^{(34)}$. Adherence to a healthy diet was assessed by the Dutch Healthy Diet index (DHDindex $)^{(35,36)}$. The original DHD-index consists of ten components, representing the Dutch Guidelines for a Healthy Diet ${ }^{(28)}$. Eight of the ten components were measured in the MetSLIM study (physical activity, vegetables, fruit, fibre, fish, SFA, trans-fatty acids and alcohol). Participants could score between 0 and 10 points, resulting in a total maximum score of 80 points. A higher score represents better adherence to the Dutch Guidelines for a Healthy Diet. Quality of life was assessed in different health domains with the 36-Item Short Form Health Survey (SF-36) questionnaire ${ }^{(37)}$.

\section{Statistical analysis}

It was calculated that a sample size of 252 participants would be required to detect a change in waist circumference of $1 \cdot 1 \mathrm{~cm}$, assuming $\alpha$ of $0 \cdot 05$, power of $80 \%$ and a dropout rate of $25 \%^{(25)}$. Eventually, 220 participants could be enrolled in the MetSLIM study during an intensive recruitment period of 17 months (see Fig. 1).

Participants who became pregnant during the study ( $n$ 5) were excluded from the analyses. Furthermore, participants with missing data on waist circumference (the primary outcome measure) at 12 months were considered dropouts and excluded from the analyses; these participants missed data on the other measures as well ( $n$ 66). As a result, data collected from 149 participants were used for statistical analysis. Participants with a C-reactive protein concentration $>10 \mathrm{mg} / \mathrm{l}$ were excluded from the analysis regarding C-reactive protein, because these concentrations reflect acute rather than chronic inflammation ${ }^{(38,39)}$. Participants who skipped whole sections of the FFQ or reported a consumption of less than $2092 \mathrm{~kJ} / \mathrm{d}(500 \mathrm{kcal} / \mathrm{d})$ or $3347 \mathrm{~kJ} / \mathrm{d}(800 \mathrm{kcal} / \mathrm{d})$, for women and men respectively, were excluded from the analyses for dietary intake $(n 5)^{(40)}$. Excessive alcohol consumption was classified as more than 21 consumptions/week for men and more than 14 consumptions/week for women.

Data were analysed with the statistical software package IBM SPSS Statistics version 22. Significance level was set at 0.05. All analyses were performed according to the intention-to-treat principle, where participants were analysed in the groups for which they were recruited, regardless of whether they actively participated in that group. Continuous variables are presented as mean and $\mathrm{SD}$, and categorical variables as number and percentage. Baseline characteristics were compared between participants in the intervention and the control group, and between completers and dropouts, with $\chi^{2}$ tests, independent-samples $t$ tests or Mann-Whitney tests. For each outcome variable, baseline results are described for those participants who had data for that variable at baseline and after 12 months. Changes in prevalence of metabolic syndrome and albuminuria were compared within the intervention and the control group with McNemar's tests. Changes in continuous effect outcomes over time were compared between the intervention and the control group by ANCOVA, with change after 12 months as the outcome variable, adjusted for the mean value of the measurements at baseline and 12 months for the respective variable ${ }^{(41)}$ and ethnicity. Although general practitioners and researchers screened for relevant medication during recruitment, a few medication users were enrolled in the study. Excluding users of medication for glucose ( $n$ 2), cholesterol ( $n$ 5) or blood pressure ( $n$ 2) from those analyses that could be influenced by medication use resulted in similar results, except for HbA1c. Medication users were therefore included in the analyses.

The effect of the treatment was compared between participants of Dutch and Turkish origin (the two largest ethnic groups in the study). To test the interaction between treatment and ethnicity, an interaction term was added to the model. For the interaction term between treatment and ethnicity, a $P$ value of $0 \cdot 20$ was considered relevant ${ }^{(42)}$. The effect of the treatment on dietary intake was not compared between Dutch and Turkish participants, because dietary intake was known for only a small number of Turkish participants in the control group ( $n 6)$.

\section{Results}

\section{Baseline characteristics and programme attendance}

Participants who dropped out ( $n 66,31 \%$ ) did not differ in baseline characteristics from the completers, except that they were more often smokers and had more often been recruited via their general practitioner (Table 1). The most important reasons for dropout were lack of time (30\%), lack of interest (26\%) and lost contact (20\%; Fig. 1).

Completers attended more often the introduction meeting of the intervention programme (76v. 51\%) and more often one or more of the three dietary group meetings than dropouts ( 85 v. 29\%). Completers also made more use of the individual dietary advice (155 (SD 52) v. 53 (SD 54) min). Participation in physical activity lessons was unfortunately incompletely registered by sport instructors; however, the lessons that were registered showed higher attendance among completers compared with dropouts in the physical activity lessons as well.

The baseline characteristics of the 149 participants who completed the study are presented in Table 2. In general, baseline characteristics were similar between the intervention and the control group. On average, the completing participants were 47.5 (SD 9.2) years old. Most of them were of Dutch ( $40 \%$ ) or Turkish origin (48\%) and female (83\%). 
Table 1 Comparison of baseline characteristics between completers and dropouts in the MetSLIM study targeting individuals of low socio-economic status and different ethnic origins with elevated waist-to-height ratio, the Netherlands, January 2013-June 2015

\begin{tabular}{|c|c|c|c|c|c|}
\hline & \multicolumn{2}{|c|}{$\begin{array}{l}\text { Completers } \\
(n \text { 149)* }\end{array}$} & \multicolumn{2}{|c|}{$\begin{array}{l}\text { Dropouts } \\
(n 66)^{*}\end{array}$} & \multirow[b]{2}{*}{$P \neq$} \\
\hline & $\begin{array}{c}n \text { or } \\
\text { Meant }\end{array}$ & $\begin{array}{l}\% \text { or } \\
\text { sD }\end{array}$ & $\begin{array}{c}n \text { or } \\
\text { Meant }\end{array}$ & $\begin{array}{l}\% \text { or } \\
\text { sD }\end{array}$ & \\
\hline Treatment group & & & & & 0.93 \\
\hline Intervention group & 80 & 54 & 35 & 53 & \\
\hline Control group & 69 & 46 & 31 & 47 & \\
\hline Recruitment strategy & & & & & 0.047 \\
\hline Invited by general practitioner & 73 & 49 & 42 & 64 & \\
\hline Invited in community centre & 76 & 51 & 24 & 36 & \\
\hline Gender & & & & & 0.13 \\
\hline Male & 25 & 17 & 17 & 26 & \\
\hline Female & 124 & 83 & 49 & 74 & \\
\hline Age (years) & 47.5 & 9.2 & 45.4 & $10 \cdot 1$ & 0.14 \\
\hline Ethnicity & & & & & 0.17 \\
\hline Dutch & 59 & 40 & 20 & 30 & \\
\hline Turkish & 71 & 48 & 35 & 53 & \\
\hline Moroccan & 6 & 4 & 7 & 11 & \\
\hline Other & 13 & 9 & 4 & 6 & \\
\hline Educational level & & & & & 0.18 \\
\hline No education & 16 & 11 & 14 & 21 & \\
\hline Lowest education (primary) & 41 & 28 & 15 & 23 & \\
\hline $\begin{array}{l}\text { Low education (lower } \\
\text { secondary) }\end{array}$ & 35 & 23 & 19 & 29 & \\
\hline Middle education & 38 & 26 & 13 & 20 & \\
\hline High education & 19 & 13 & 5 & 8 & \\
\hline Employment status & & & & & 0.47 \\
\hline No paid job & 83 & 56 & 37 & 64 & \\
\hline Part-time job (<32 h/week) & 40 & 27 & 11 & 19 & \\
\hline Full-time job ( $\geq 32 \mathrm{~h} /$ week) & 25 & 17 & 10 & 17 & \\
\hline Household situation & & & & & 0.19 \\
\hline Single occupant & 30 & 20 & 10 & 18 & \\
\hline Living with partner & 27 & 18 & 12 & 21 & \\
\hline Living with partner and child(ren) & 67 & 46 & 32 & 56 & \\
\hline Single parent living with child(ren) & 23 & 16 & 3 & 5 & \\
\hline Smoking status & & & & & 0.031 \\
\hline Current & 30 & 20 & 22 & 38 & \\
\hline Former & 39 & 26 & 11 & 19 & \\
\hline Never & 79 & 53 & 25 & 43 & \\
\hline Alcohol consumption & & & & & 0.22 \\
\hline No consumption & 76 & 60 & 39 & 74 & \\
\hline Low to moderate consumption & 42 & 33 & 11 & 21 & \\
\hline Excessive consumption & 8 & 6 & 3 & 6 & \\
\hline Metabolic syndrome & & & & & 0.60 \\
\hline No & 102 & 72 & 37 & 69 & \\
\hline Yes & 39 & 28 & 17 & 31 & \\
\hline $\begin{array}{l}\text { Family history of type } 2 \text { diabetes } \\
\text { in first-degree relative }\end{array}$ & & & & & 0.88 \\
\hline No & 89 & 61 & 36 & 62 & \\
\hline Yes & 57 & 39 & 22 & 38 & \\
\hline
\end{tabular}

${ }^{*}$ Employment status: completer $n$ 148, dropout $n$ 58; household situation: completer $n 147$, dropout $n 57$; smoking status: completer $n 148$, dropout $n$ 58; alcohol consumption: completer $n 126$, dropout $n$ 53; metabolic syndrome: completer $n 141$, dropout $n 54$; family history of type 2 diabetes in first-degree relative: completer $n 146$, dropout $n 58$.

†Data are expressed as $n$ and \% for categorical variables; or mean and SD for continuous variables.

$\ddagger P$ value of $x^{2}$ tests or independent-samples $t$ tests.

Thirty-eight per cent of them had completed no education or primary school only, and $56 \%$ had no paid job. The latter were mostly househusband/housewife (35\%), disabled $(18 \%)$ or unemployed/looking for a job (15\%).

Intervention effects on cardiometabolic risk factors After 12 months, beneficial intervention effects were observed for cardiometabolic risk factors (Table 3 ). Mean difference in change in waist circumference was $-3.3 \mathrm{~cm}$
(95\% CI $-4 \cdot 7,-1 \cdot 8$ ) between the two groups. Also, greater reductions were observed in weight $(\beta=-2 \cdot 2 \mathrm{~kg}, 95 \%$ CI $-3 \cdot 7,-0 \cdot 8)$, BMI $\left(\beta=-0.8 \mathrm{~kg} / \mathrm{m}^{2}, 95 \% \mathrm{CI}-1 \cdot 3,-0 \cdot 3\right)$, WHtR $(\beta=-0.020,95 \% \mathrm{CI}-0.028,-0.011)$ and fat percentage $(\beta=-0 \cdot 9 \%, 95 \% \mathrm{CI}-1 \cdot 8,-0 \cdot 1)$ in the intervention group compared with the control group.

Apart from waist circumference, no significant improvements were observed for other components of the metabolic syndrome. Metabolic syndrome prevalence did not change significantly in either the intervention group (from $18 / 68$ to $18 / 68$ after 12 months; $P=1.00$ ) or the control group (from $16 / 60$ to $20 / 60$ after 12 months; $P=0.29$ ). The intervention group had greater improvements in total cholesterol $(\beta=-0.33 \mathrm{mmol} / 1,95 \%$ CI $-0.56,-0 \cdot 10)$ and LDL cholesterol $(\beta=-0.35 \mathrm{mmol} / 1,95 \%$ CI $-0.56,-0.14)$ compared with the control group. Albuminuria was rare in both the intervention group (from 1/73 to $3 / 73$ after 12 months; $P=0.50$ ) and the control group (from $1 / 58$ to $2 / 58$ after 12 months; $P=1 \cdot 00$ ).

\section{Intervention effects on dietary intake and physical activity}

After 12 months, the intervention group reported an increased fibre intake compared with the control group ( $\beta=1.5 \mathrm{~g} / 4184 \mathrm{~kJ}(1000 \mathrm{kcal}), 95 \%$ CI $0 \cdot 3,2 \cdot 7$; Table 4$)$. The intervention group also reported a reduction in energy intake $(\beta=-1359 \mathrm{~kJ}, \quad 95 \%$ CI $-3082,363$ $(\beta=-325 \mathrm{kcal}, 95 \% \mathrm{CI}-736,87), P=0 \cdot 12)$. Additionally, the intervention group reported a decrease in total minutes of physical activity compared with the control group ( $\beta=-573 \mathrm{~min} /$ week, $95 \% \mathrm{CI}-1126,-21)$.

\section{Intervention effects on quality of life}

The intervention group after 12 months showed greater improvement in the domains 'health transition' (i.e. selfrated health compared with 1 year ago) and 'general health' (i.e. their own self-reported health and their selfrated health compared with that of others) compared with the control group $(P<0 \cdot 001)$. Other changes within domains of quality of life were not different between the groups (Table 5).

\section{Intervention effects among different ethnic groups}

In general, the intervention effects were more beneficial among participants of Dutch origin than among participants of Turkish origin, especially for the different measures of obesity (see online supplementary material, Supplemental Tables 1 to 3). Intervention effect on waist circumference $(P$ for interaction $=0.14)$ among participants of Dutch origin was $-4.8 \mathrm{~cm}(95 \% \mathrm{CI}-7.7,-2 \cdot 0)$ compared with $-2 \cdot 7 \mathrm{~cm}(95 \% \mathrm{CI}-4 \cdot 2,-1 \cdot 2)$ among participants of Turkish origin. For total physical activity ( $P$ for interaction $=0.018$ ) and light-intensity physical activity $(P$ for interaction $=0.006$ ), the intervention effect was disadvantageous for participants of Turkish origin only 


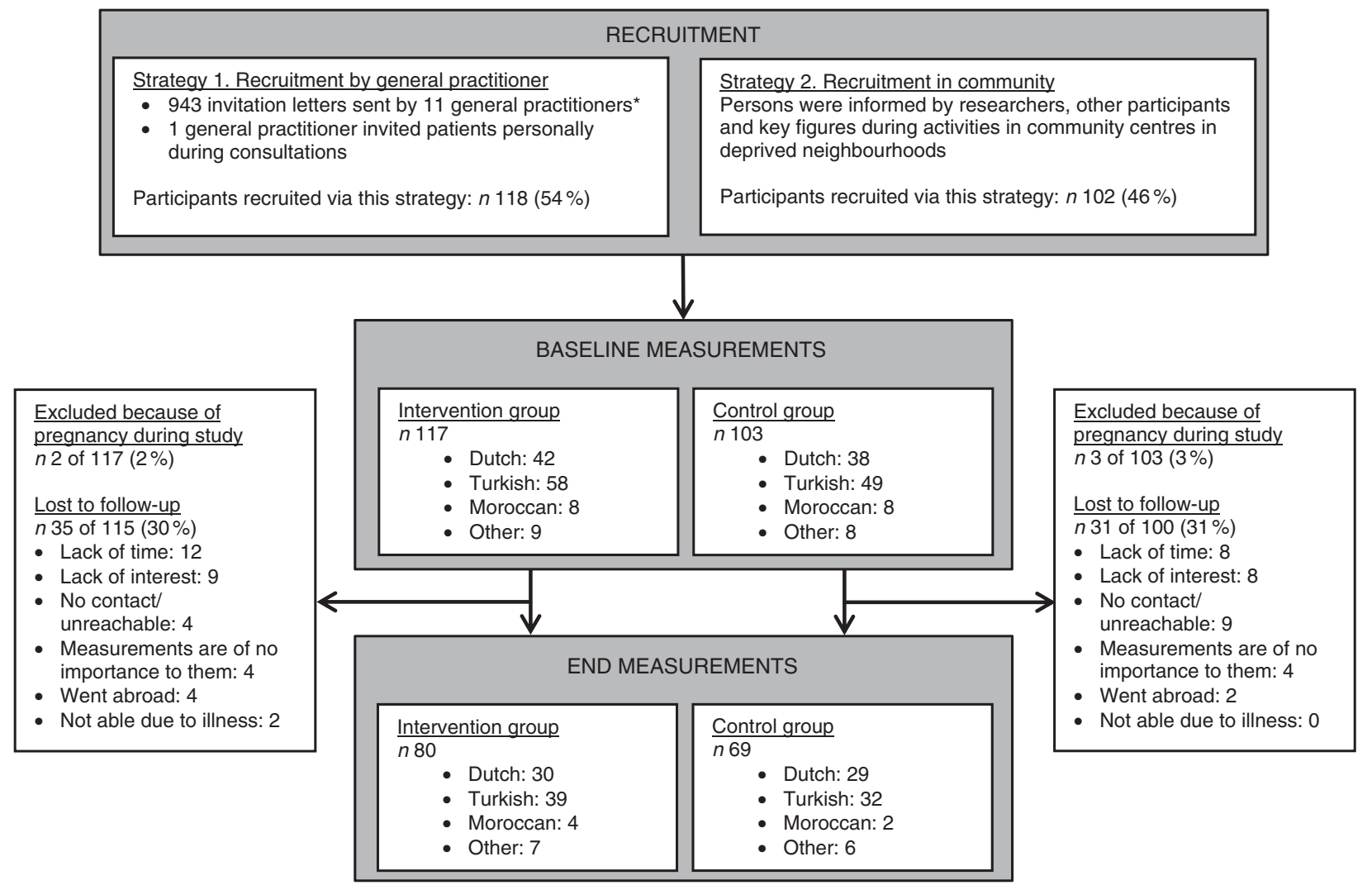

Fig 1 Flow diagram of the MetSLIM study. *Invitation letters were sent to individuals assumed to be Dutch ( $n$ 450), Turkish ( $n$ 423) or Moroccan $(n 70)$

$(\beta=-1215 \mathrm{~min} /$ week, $95 \%$ CI $-2039, \quad-390$ for total amount of physical activity; $\beta=-1030 \mathrm{~min} /$ week, $95 \% \mathrm{CI}$ $-1761,-299$ for light-intensity physical activity).

\section{Discussion}

The results of this 1-year intervention study that targeted low-SES individuals of different ethnic origins are promising and show that a lifestyle intervention carried out in socio-economically deprived neighbourhoods can be successful. The lifestyle intervention significantly improved obesity-related measures such as waist circumference, WHtR, body weight, fat percentage and BMI. The lifestyle intervention did not affect prevalence of metabolic syndrome or components of metabolic syndrome, apart from waist circumference, within 12 months. However, total cholesterol and LDL cholesterol did improve significantly. Significant changes in lifestyle were observed for fibre intake (relative intake increased in the intervention group) and total minutes of selfreported physical activity (reduced in the intervention group) only. The intervention group also showed, although not significantly, a reduction in energy intake. With regard to quality of life, participants in the intervention showed improvements in 'general health' and 'health transition'. Overall, our data support an improvement in cardiometabolic risk and quality of life in the intervention group compared with the control group.

Our study, an adapted version of the SLIM study, was targeted at persons with low SES of different ethnic origins $^{(25)}$. In the SLIM study, weight loss and reduction in waist circumference were significantly different after 12 months between the intervention and the control group $(-2.7 \mathrm{~kg},-3.5 \mathrm{~cm}$ in the intervention group and $-0.2 \mathrm{~kg}$, $-1.4 \mathrm{~cm}$ in the control group $)^{(10)}$. This is comparable with our findings. The achieved reduction of waist circumference in our intervention group is also comparable to the results of a primary-care-based intervention study based on the DPP by Ma et al. ${ }^{(43)}$ among participants with predominantly high SES. Our findings of reduction in weight and total cholesterol are comparable with another effect study of the DPP intervention translated to a community setting (i.e. the YMCA) ${ }^{(44)}$. We did not reproduce the beneficial results with regard to blood pressure, HDL cholesterol, TAG and fasting glucose after 12 months reported in other studies based on the $\mathrm{DPP}^{(5,7,45)}$, or the reduction in fasting insulin levels after 12 months in the SLIM study ${ }^{(10)}$. However, in those studies, participants were selected on the basis of having pre-diabetes, metabolic syndrome or impaired glucose tolerance, or on the basis of being at high risk of developing diabetes (risk score tool), whereas participants in our study were included on the basis of elevated WHtR only. 
Table 2 Baseline characteristics of participants $(n$ 149) in the MetSLIM study targeting individuals of low socio-economic status and different ethnic origins with elevated waist-to-height ratio, the Netherlands, January 2013-June 2015

\begin{tabular}{|c|c|c|c|c|c|}
\hline & \multicolumn{2}{|c|}{$\begin{array}{c}\text { INT } \\
(n 80)^{*}\end{array}$} & \multicolumn{2}{|c|}{$\begin{array}{l}\mathrm{CON} \\
(n 69)^{*}\end{array}$} & \multirow[b]{2}{*}{$P \neq$} \\
\hline & $\begin{array}{c}n \text { or } \\
\text { Meant }\end{array}$ & $\begin{array}{l}\% \text { or } \\
\text { SD† }\end{array}$ & $\begin{array}{c}n \text { or } \\
\text { Meant }\end{array}$ & $\begin{array}{l}\% \text { or } \\
\text { SD† }\end{array}$ & \\
\hline \multicolumn{5}{|l|}{ Recruitment strategy } & 0.29 \\
\hline Invited by general practitioner & 36 & 45 & 37 & 54 & \\
\hline Invited in community centre & 44 & 55 & 32 & 46 & \\
\hline \multicolumn{5}{|l|}{ Gender } & 0.29 \\
\hline Male & 11 & 14 & 14 & 20 & \\
\hline Female & 69 & 86 & 55 & 80 & \\
\hline Age (years) & 47.9 & 7.9 & $47 \cdot 0$ & 10.6 & 0.57 \\
\hline \multicolumn{5}{|l|}{ Ethnicity } & 0.89 \\
\hline Dutch & 30 & 38 & 29 & 42 & \\
\hline Turkish & 39 & 49 & 32 & 46 & \\
\hline Moroccan & 4 & 5 & 2 & 3 & \\
\hline Other & 7 & 9 & 6 & 9 & \\
\hline \multicolumn{5}{|l|}{ Educational level } & $0 \cdot 10$ \\
\hline No education & 12 & 15 & 4 & 6 & \\
\hline Lowest education (primary) & 24 & 30 & 17 & 25 & \\
\hline $\begin{array}{l}\text { Low education (lower } \\
\text { secondary) }\end{array}$ & 20 & 25 & 15 & 22 & \\
\hline Middle education & 18 & 23 & 20 & 29 & \\
\hline High education & 6 & 8 & 13 & 19 & \\
\hline \multicolumn{5}{|l|}{ Employment status } & 0.11 \\
\hline No paid job & 45 & 57 & 38 & 55 & \\
\hline Part-time job (<32 h/week) & 25 & 32 & 15 & 22 & \\
\hline Full-time job ( $\geq 32 \mathrm{~h} /$ week) & 9 & 11 & 16 & 23 & \\
\hline \multicolumn{5}{|l|}{ Household situation } & 0.13 \\
\hline Alone & 17 & 22 & 13 & 19 & \\
\hline Together with partner & 16 & 21 & 11 & 16 & \\
\hline $\begin{array}{l}\text { Together with partner and } \\
\text { child(ren) }\end{array}$ & 38 & 49 & 29 & 42 & \\
\hline $\begin{array}{l}\text { Single parent living with child } \\
\text { (ren) }\end{array}$ & 7 & 9 & 16 & 23 & \\
\hline \multicolumn{5}{|l|}{ Smoking status } & 0.92 \\
\hline Current & 15 & 19 & 15 & 22 & \\
\hline Former & 21 & 27 & 18 & 26 & \\
\hline Never & 43 & 54 & 36 & 52 & \\
\hline \multicolumn{6}{|l|}{ Alcohol consumption } \\
\hline No consumption & 41 & 65 & 35 & 56 & 0.28 \\
\hline Low to moderate consumption & 20 & 32 & 22 & 35 & \\
\hline Excessive consumption & 2 & 3 & 6 & 10 & \\
\hline \multicolumn{5}{|l|}{ Metabolic syndrome } & 0.56 \\
\hline No & 52 & 70 & 50 & 75 & \\
\hline Yes & 22 & 30 & 17 & 25 & \\
\hline \multicolumn{5}{|l|}{ Metabolic syndrome components } & 0.43 \\
\hline 0 & 8 & 11 & 11 & 16 & \\
\hline 1 & 16 & 22 & 20 & 30 & \\
\hline 2 & 28 & 38 & 19 & 28 & \\
\hline 3 & 14 & 19 & 7 & 10 & \\
\hline 4 & 7 & 9 & 9 & 13 & \\
\hline & 1 & 1 & 1 & 1 & \\
\hline \multicolumn{5}{|l|}{$\begin{array}{l}\text { Family history of type } 2 \text { diabetes } \\
\text { in first-degree relative }\end{array}$} & 0.39 \\
\hline No & 45 & 58 & 44 & 65 & \\
\hline Yes & 33 & 42 & 24 & 35 & \\
\hline \multicolumn{5}{|l|}{ History of hyperglycaemia } & 0.55 \\
\hline No & 71 & 90 & 63 & 93 & \\
\hline Yes & 8 & 10 & 5 & 7 & \\
\hline \multicolumn{5}{|l|}{ History of hypercholesterolaemia } & 0.54 \\
\hline No & 65 & 82 & 54 & 78 & \\
\hline Yes & 14 & 18 & 15 & 22 & \\
\hline \multicolumn{5}{|l|}{ History of hypertension } & 0.37 \\
\hline No & 66 & 88 & 62 & 93 & \\
\hline Yes & 9 & 12 & 5 & 7 & \\
\hline
\end{tabular}

INT, intervention group; CON, control group.

*Employment status: INT $n 79$, CON $n$ 69; household situation: INT $n 78$ CON $n 69$; smoking status: INT $n 79$, CON $n 69$; alcohol consumption: INT $n$ 63 , CON $n 63$; metabolic syndrome: INT $n 74$, CON $n 67$; metabolic syndrome components: INT $n 74$, CON $n 67$; family history of type 2 diabetes in first-degree relative: INT $n 78, \mathrm{CON} n 68$; history of hypercholesterolaemia: INT $n 79$, CON $n 69$; history of hypertension: INT $n 75$, CON $n 67$.

tData are expressed as $n$ and \% for categorical variables; or mean and SD for continuous variables.

$\ddagger P$ value of $x^{2}$ tests or independent-samples $t$ tests.
Because medication users were excluded during recruitment, a relatively healthy population was enrolled in our study. This might explain why we found no significant changes in blood pressure, HDL cholesterol, TAG and fasting glucose. Only $28 \%$ of the participants in the MetSLIM study had metabolic syndrome; this is comparable to data on the general Dutch population aged 30-70 years (34\% of men and $24 \%$ of women) ${ }^{(46)}$. Furthermore, the cut-off value of 0.5 might have been too low to select participants with metabolic syndrome, especially for the younger adults. A recent study identified a WHtR cut-off value of 0.580 as optimal for discriminating individuals with metabolic syndrome among younger adults ${ }^{(47)}$.

Despite the beneficial changes in obesity measures, the intervention group did not report significant improvements in energy intake and physical activity. One would expect improvements in obesity measures to result from positive lifestyle changes. As obesity measures are expected to be more objective than self-reported lifestyle data, one could debate whether the self-reported lifestyle data in the current study were completely reliable. Questionnaire data can be subject to socially desirable answers and depend on participants' literacy skills, which might be relatively low in our target group. In this case, it could be that the intervention group got a more realistic view of their PA level and reported less PA, whereas the control group gave socially desirable answers and reported to engage in more PA.

In general, intervention effects were more beneficial among participants of Dutch origin than among participants of Turkish origin. However, these two groups were not completely comparable in the present study as they differed in, among other things, age, education level and intervention location (see Supplemental Table 1). Therefore, the results cannot be attributed to ethnicity only. In any case, the results imply that the intervention was less effective in the Turkish group that was reached in the present study and, in order to achieve greater effects, further adaptations for this group should be considered.

In the present study, low SES was determined by neighbourhood. A disadvantage of selecting participants on the basis of the neighbourhood they lived in was that higher educated persons were also able to participate in the study. However, when we included only the participants with a low educational level in our analyses, this did not change our conclusion significantly. In fact, the intervention effects seemed slightly better when excluding the higher educated participants (data not shown).

The dropout rate in MetSLIM (31\%) was relatively high compared with SLIM (10\% after the first year), but comparable to dropout rates in similar studies among low-SES populations $^{(48)}$ or ethnic minorities ${ }^{(20,49)}$. It can be questioned whether dropout can be reduced by further adaptations to the intervention study protocol. Reasons for dropout that were quite often mentioned were 'no time' 
Table 3 Changes in cardiometabolic risk factors from baseline to 12 months among participants $(n$ 149) in the MetSLIM study targeting individuals of low socio-economic status and different ethnic origins with elevated waist-to-height ratio, the Netherlands, January 2013-June 2015*

\begin{tabular}{|c|c|c|c|c|c|c|c|}
\hline & \multicolumn{2}{|c|}{ INT† } & \multicolumn{2}{|c|}{$\mathrm{CON} \dagger$} & \multicolumn{2}{|c|}{ Differences between groups } & \multirow[b]{2}{*}{$P \ddagger$} \\
\hline & Mean & SD & Mean & SD & $\beta$ & $95 \% \mathrm{Cl}$ & \\
\hline Anthropometric measures & \multicolumn{2}{|c|}{$n 80$} & \multicolumn{2}{|c|}{$n 69$} & & & \\
\hline \multicolumn{8}{|l|}{ Waist circumference $(\mathrm{cm})$} \\
\hline Baseline & $99 \cdot 1$ & $11 \cdot 2$ & $97 \cdot 6$ & $11 \cdot 2$ & & & \\
\hline Change after 12 months & -3.4 & $4 \cdot 7$ & -0.2 & $4 \cdot 3$ & $-3 \cdot 3$ & $-4 \cdot 7,-1 \cdot 8$ & $<0.001$ \\
\hline \multicolumn{8}{|l|}{ Weight $(\mathrm{kg})$} \\
\hline Baseline & $83 \cdot 7$ & $14 \cdot 7$ & $82 \cdot 7$ & $14 \cdot 1$ & & & \\
\hline Change after 12 months & $-2 \cdot 2$ & 5.4 & -0.1 & 3.6 & $-2 \cdot 2$ & $-3 \cdot 7,-0.8$ & 0.003 \\
\hline \multicolumn{8}{|l|}{ BMI $\left(\mathrm{kg} / \mathrm{m}^{2}\right)$} \\
\hline Baseline & $31 \cdot 7$ & 4.7 & $30 \cdot 5$ & $5 \cdot 0$ & & & \\
\hline Change after 12 months & -0.8 & 1.9 & -0.1 & $1 \cdot 3$ & -0.8 & $-1 \cdot 3,-0 \cdot 3$ & 0.003 \\
\hline \multicolumn{8}{|l|}{ Waist-to-height ratio } \\
\hline Baseline & 0.610 & 0.061 & 0.593 & 0.070 & & & \\
\hline Change after 12 months & -0.021 & 0.028 & -0.001 & 0.026 & -0.020 & $-0.028,-0.011$ & $<0.001$ \\
\hline \multicolumn{8}{|l|}{ Body fat (\%) } \\
\hline Baseline & $37 \cdot 5$ & $6 \cdot 8$ & 35.9 & $7 \cdot 9$ & & & \\
\hline Change after 12 months & -0.7 & $2 \cdot 6$ & 0.2 & $2 \cdot 6$ & -0.9 & $-1 \cdot 8,-0 \cdot 1$ & 0.033 \\
\hline Blood pressure & & & & & & & \\
\hline Systolic blood pressure (mn & & & & & & & \\
\hline Baseline & $117 \cdot 3$ & $20 \cdot 0$ & $116 \cdot 6$ & $15 \cdot 0$ & & & \\
\hline Change after 12 months & $-0 \cdot 3$ & $10 \cdot 4$ & -1.0 & $11 \cdot 2$ & 0.6 & $-2 \cdot 9,4 \cdot 1$ & 0.73 \\
\hline Diastolic blood pressure $(\mathrm{m}$ & & & & & & & \\
\hline Baseline & $77 \cdot 1$ & $10 \cdot 7$ & $74 \cdot 7$ & 9.5 & & & 0.46 \\
\hline Change after 12 months & $-1 \cdot 3$ & 6.9 & -0.3 & $7 \cdot 8$ & -0.9 & $-3 \cdot 4,1.5$ & \\
\hline Blood markers & & & & & & & \\
\hline Fasting glucose $(\mathrm{mmol} / \mathrm{l})$ & & & & & & & \\
\hline Baseline & $5 \cdot 38$ & 0.91 & $5 \cdot 30$ & $1 \cdot 34$ & & & \\
\hline Change after 12 months & -0.22 & 0.57 & -0.17 & 0.51 & -0.06 & $-0.23,0.12$ & 0.53 \\
\hline Fasting insulin $(\mathrm{pmol} / \mathrm{l})$ & & & & & & & \\
\hline Baseline & $66 \cdot 73$ & $38 \cdot 71$ & $71 \cdot 27$ & $30 \cdot 89$ & & & \\
\hline Change after 12 months & -1.94 & 39.05 & -0.84 & 44.73 & -0.57 & $-15 \cdot 28,14 \cdot 14$ & 0.94 \\
\hline $\mathrm{HbA} 1 \mathrm{c}(\mathrm{mmol} / \mathrm{mol})$ & & & & & & & \\
\hline Baseline & $37 \cdot 23$ & $5 \cdot 81$ & $36 \cdot 83$ & $9 \cdot 30$ & & & \\
\hline Change after 12 months & 1.09 & 3.43 & 0.28 & 2.63 & 0.84 & $-0.23,1.91$ & $0 \cdot 12 \S$ \\
\hline HOMA-IR & & & & & & & \\
\hline Baseline & $2 \cdot 67$ & 1.68 & $2 \cdot 86$ & 1.65 & & & \\
\hline Change after 12 months & -0.19 & 1.69 & -0.13 & 1.63 & -0.09 & $-0.68,0.50$ & 0.76 \\
\hline Total cholesterol $(\mathrm{mmol} / \mathrm{l})$ & & & & & & & \\
\hline Baseline & 5.56 & 0.95 & $5 \cdot 28$ & 0.87 & & & \\
\hline Change after 12 months & -0.26 & 0.61 & 0.03 & 0.71 & -0.33 & $-0.56,-0.10$ & 0.005 \\
\hline HDL cholesterol $(\mathrm{mmol} / \mathrm{l})$ & & & & & & & \\
\hline Baseline & 1.41 & 0.32 & 1.44 & 0.39 & & & \\
\hline Change after 12 months & 0.04 & 0.19 & 0.00 & 0.21 & 0.05 & $-0.02,0.12$ & 0.14 \\
\hline LDL cholesterol (mmol/l) & & & & & & & \\
\hline Baseline & 3.48 & 0.87 & $3 \cdot 20$ & 0.82 & & & \\
\hline Change after 12 months & -0.28 & 0.58 & 0.04 & 0.64 & -0.35 & $-0.56,-0.14$ & 0.001 \\
\hline TAG $(\mathrm{mmol} / \mathrm{l})$ & & & & & & & \\
\hline Baseline & 1.45 & 0.77 & 1.40 & 0.67 & & & \\
\hline Change after 12 months & -0.06 & 0.50 & -0.02 & 0.53 & -0.05 & $-0.23,0.13$ & 0.57 \\
\hline Alanine aminotransferase & & & & & & & \\
\hline Baseline & 21.75 & 8.65 & 24.62 & 13.59 & & & \\
\hline Change after 12 months & -1.07 & $7 \cdot 4$ & 1.43 & 12.94 & -2.50 & $-6 \cdot 19,1 \cdot 19$ & 0.18 \\
\hline Aspartate aminotransferase & & & & & & & \\
\hline Baseline & 23.01 & 4.96 & 22.95 & 6.03 & & & \\
\hline Change after 12 months & -1.83 & 4.65 & -0.25 & $7 \cdot 12$ & -1.43 & $-3.53,0.66$ & 0.18 \\
\hline Y-Glutamyl transferase $(\mathrm{U} / \mathrm{l})$ & & & & & & & \\
\hline Baseline & 24.51 & $17 \cdot 96$ & $25 \cdot 75$ & $23 \cdot 16$ & & & \\
\hline Change after 12 months & -2.59 & 11.99 & 1.07 & $16 \cdot 66$ & $-3 \cdot 65$ & $-8.70,1.39$ & 0.15 \\
\hline Creatinine (umol/l) & & & & & & & \\
\hline Baseline & $66 \cdot 14$ & $9 \cdot 20$ & 65.59 & $12 \cdot 62$ & & & \\
\hline Change after 12 months & 0.72 & $5 \cdot 32$ & 2.48 & 6.56 & $-1 \cdot 75$ & $-3.78,0.27$ & 0.09 \\
\hline Uric acid $(\mathrm{mmol} / \mathrm{l})$ & & & & & & & \\
\hline Baseline & 0.29 & 0.07 & 0.27 & 0.07 & & & \\
\hline Change after 12 months & -0.014 & 0.035 & 0.000 & 0.047 & -0.014 & $-0.028,0.001$ & 0.07 \\
\hline C-reactive protein $(\mathrm{mg} / \mathrm{l})$ & & & & & & & \\
\hline Baseline & 3.07 & $2 \cdot 37$ & $2 \cdot 73$ & $2 \cdot 38$ & & & \\
\hline Change after 12 months & 0.09 & 2.00 & 0.17 & $2 \cdot 32$ & $-0 \cdot 19$ & $-0.99,0.62$ & 0.65 \\
\hline
\end{tabular}

INT, intervention group; CON, control group; HbA1c, glycated Hb; HOMA-IR, homeostatic model assessment of insulin resistance.

${ }^{\star}$ Date are expressed as mean and SD; or $\beta$ and $95 \% \mathrm{Cl}$.

†Body fat: INT $n$ 76, CON $n$ 69; fasting insulin: INT $n$ 71, CON $n$ 61; HbA1c: INT $n$ 70, CON $n$ 60; HOMA-IR: INT $n$ 71, CON $n$ 61; TAG: INT $n$ 72, CON $n$ 60; alanine aminotransferase: INT $n 71$, CON $n$ 61; aspartate aminotransferase: INT $n 71$, CON $n$ 60; $\gamma$-glutamyl transferase: INT $n$ 71, CON $n$ 61; uric acid: INT $n$ 71, CON $n 61$; C-reactive protein $\leq 10 \mathrm{mg} / \mathrm{l}$ : INT $n 61$, CON $n 56$.

$\ddagger P$ value for difference between treatment groups in ANCOVA test, adjusted for ethnicity and individuals' mean value of the measurements at baseline and 12 months for the respective variable.

$\S$ Excluding participants using relevant medication $(n 2)$ from the analysis resulted in a $P$ value of 0.044 . 
Table 4 Changes in dietary intake ( $n$ 98) and physical activity $(n 125)$ from baseline to 12 months among participants in the MetSLIM study targeting individuals of low socio-economic status and different ethnic origins with elevated waist-to-height ratio, the Netherlands, January 2013-June $2015^{\star}$

\begin{tabular}{|c|c|c|c|c|c|c|c|}
\hline & \multicolumn{2}{|c|}{ INT† } & \multicolumn{2}{|c|}{ CON† } & \multicolumn{2}{|c|}{ Differences between groups } & \multirow[b]{2}{*}{$P \ddagger$} \\
\hline & Mean & SD & Mean & SD & $\beta$ & $95 \% \mathrm{Cl}$ & \\
\hline Dietary intake & \multicolumn{2}{|c|}{$n 61$} & \multicolumn{2}{|c|}{$n 37$} & & & \\
\hline Energy intake (kJ/d) & & & & & & & \\
\hline Baseline & 10294 & 4744 & 9364 & 3674 & & & \\
\hline Change after 12 months & -1780 & 4652 & -579 & 2594 & -1359 & $-3082,363$ & $0 \cdot 12$ \\
\hline \multicolumn{8}{|l|}{ Energy intake $(\mathrm{kcal} / \mathrm{d})$} \\
\hline Baseline & 2460 & 1134 & 2238 & 878 & & & \\
\hline Change after 12 months & -425 & 1112 & -138 & 620 & -325 & $-736,87$ & 0.12 \\
\hline \multicolumn{8}{|l|}{ Total protein (\% of energy) } \\
\hline Baseline & $16 \cdot 1$ & $2 \cdot 7$ & $16 \cdot 2$ & $2 \cdot 3$ & & & \\
\hline Change after 12 months & 0.8 & 3.0 & 0.3 & $2 \cdot 2$ & 0.7 & $-0.5,1.8$ & 0.25 \\
\hline \multicolumn{8}{|l|}{ Total fat ( $\%$ of energy) } \\
\hline Baseline & 34.5 & $6 \cdot 2$ & $34 \cdot 8$ & $5 \cdot 4$ & & & \\
\hline Change after 12 months & -0.1 & $8 \cdot 1$ & -0.3 & 3.9 & -0.9 & $-3 \cdot 8,2 \cdot 0$ & 0.55 \\
\hline \multicolumn{8}{|l|}{ Saturated fat ( $\%$ of energy) } \\
\hline Baseline & $12 \cdot 6$ & 3.0 & $12 \cdot 5$ & $2 \cdot 9$ & & & \\
\hline Change after 12 months & -0.3 & 3.7 & -0.0 & 2.3 & -0.8 & $-2.2,0.5$ & 0.22 \\
\hline \multicolumn{8}{|c|}{ Total carbohydrates ( $\%$ of energy) } \\
\hline Baseline§ & $43 \cdot 3$ & $7 \cdot 1$ & $40 \cdot 3$ & $6 \cdot 7$ & & & \\
\hline Change after 12 months & -0.8 & $8 \cdot 2$ & 0.1 & 4.5 & 0.3 & $-2 \cdot 7,3 \cdot 3$ & 0.85 \\
\hline \multicolumn{8}{|l|}{ Fibre (g/4184 kJ (1000 kcal)) } \\
\hline Baseline & $10 \cdot 9$ & $3 \cdot 1$ & $10 \cdot 8$ & $2 \cdot 8$ & & & \\
\hline Change after 12 months & 0.8 & $3 \cdot 3$ & -0.2 & $2 \cdot 1$ & 1.5 & $0.3,2 \cdot 7$ & 0.016 \\
\hline \multicolumn{8}{|l|}{ Fruit intake $(\mathrm{g} / \mathrm{d})$} \\
\hline Baseline & 205 & 258 & 201 & 249 & & & \\
\hline Change after 12 months & -5 & 261 & -32 & 201 & 54 & $-36,144$ & 0.23 \\
\hline \multicolumn{8}{|l|}{ Vegetable intake $(\mathrm{g} / \mathrm{d})$} \\
\hline Baseline & 148 & 123 & 159 & 133 & & & \\
\hline Change after 12 months & -3 & 122 & -21 & 98 & 20 & $-30,70$ & 0.43 \\
\hline \multicolumn{8}{|c|}{ Dutch Healthy Diet index (0-80 scale) } \\
\hline Baseline & $57 \cdot 0$ & 9.9 & 57.6 & 9.8 & & & \\
\hline Change after 12 months & 0.3 & $9 \cdot 3$ & $-0 \cdot 1$ & $6 \cdot 8$ & 1.5 & $-2 \cdot 2,5 \cdot 2$ & 0.42 \\
\hline Physical activity (PA) & \multicolumn{2}{|c|}{$n 62$} & \multicolumn{2}{|c|}{$n 63$} & & & \\
\hline \multicolumn{8}{|l|}{ Total PA (min/week) } \\
\hline Baseline & 2372 & 1784 & 2274 & 1301 & & & \\
\hline Change after 12 months & -362 & 1447 & 211 & 1611 & -573 & $-1126,-21$ & 0.042 \\
\hline \multicolumn{8}{|l|}{ Light PA (min/week) } \\
\hline Baseline & 1608 & 1106 & 1677 & 1067 & & & \\
\hline Change after 12 months & -243 & 1071 & 248 & 1344 & -434 & $-873,5$ & 0.053 \\
\hline \multicolumn{8}{|l|}{ Moderate PA (min/week) } \\
\hline Baseline & 643 & 1098 & 457 & 525 & & & \\
\hline Change after 12 months & -79 & 894 & -9 & 657 & -54 & $-333,225$ & 0.70 \\
\hline \multicolumn{8}{|l|}{ Vigorous PA (min/week) } \\
\hline Baseline & 120 & 239 & 141 & 423 & & & \\
\hline Change after 12 months & -40 & 193 & -28 & 327 & -27 & $-118,64$ & 0.56 \\
\hline
\end{tabular}

INT, intervention group; CON, control group.

${ }^{*}$ Data are expressed as mean and SD; or $\beta$ and $95 \% \mathrm{Cl}$.

†Dutch Healthy Diet index: INT $n 60, \operatorname{CON} n 36$.

$\ddagger P$ value for difference between treatment groups in ANCOVA test, adjusted for ethnicity and individuals' mean value of the measurements at baseline and 12 months for the respective variable.

$\S$ Significantly different between INT and CON at baseline.

and 'no interest'. Participants elaborated on this by mentioning that they had conflicting issues to worry about in life, for example sick relatives. Other researchers have reported that 'life stressors' can interfere with participation in a lifestyle intervention ${ }^{(48)}$. Such dropout is hard to prevent in a lifestyle intervention focusing exclusively on diet and physical activity. Furthermore, some of the reasons for dropout (e.g. moving to another area) or exclusion from the analyses (e.g. pregnancy) cannot be prevented by adaptation measures.
A limitation of our study was that some participants did not fill in the questionnaires or did not go for their blood test at the medical laboratory. For future studies, it could help to limit the number of measurements (several participants expressed dissatisfaction about the large burden of the measurements) and focus on completing the most important measurements. It would also be advisable to combine measurements; that is, have all measurements at the same time and location. However, that may be practically challenging in community settings. 
Table 5 Changes in quality of life from baseline to 12 months among participants $(n 129)$ in the MetSLIM study targeting individuals of low socio-economic status and different ethnic origins with elevated waist-to-height ratio, the Netherlands, January 2013-June 2015*

\begin{tabular}{|c|c|c|c|c|c|c|c|}
\hline & \multicolumn{2}{|c|}{ INT $(n$ 64)† } & \multicolumn{2}{|c|}{$\mathrm{CON}(n$ 65)† } & \multicolumn{2}{|c|}{ Differences between groups } & \multirow[b]{2}{*}{$P \ddagger$} \\
\hline & Mean & SD & Mean & SD & $\beta$ & $95 \% \mathrm{Cl}$ & \\
\hline \multicolumn{8}{|l|}{ Health transition } \\
\hline Baseline & 43.7 & $20 \cdot 6$ & 50.4 & 23.2 & & & \\
\hline Change after 12 months & $22 \cdot 2$ & $32 \cdot 7$ & -0.4 & 28.5 & 21.6 & $10 \cdot 7,32 \cdot 5$ & $<0.001$ \\
\hline \multicolumn{8}{|l|}{ General health } \\
\hline Baseline & 58.4 & 21.4 & $60 \cdot 6$ & 17.9 & & & \\
\hline Change after 12 months & $8 \cdot 2$ & $16 \cdot 8$ & -1.5 & $12 \cdot 3$ & $9 \cdot 2$ & $3 \cdot 9,14.5$ & $<0.001$ \\
\hline \multicolumn{8}{|l|}{ Physical functioning } \\
\hline Baseline & 74.8 & 23.2 & 78.5 & $20 \cdot 2$ & & & \\
\hline Change after 12 months & $5 \cdot 0$ & $20 \cdot 8$ & 2.9 & $17 \cdot 0$ & 1.5 & $-5 \cdot 1,8 \cdot 1$ & 0.65 \\
\hline \multicolumn{8}{|l|}{ Role physical } \\
\hline Baseline & $70 \cdot 0$ & $40 \cdot 6$ & 71.8 & 38.8 & & & \\
\hline Change after 12 months & -7.5 & $36 \cdot 0$ & -3.2 & $46 \cdot 3$ & -4.7 & $-19 \cdot 9,10 \cdot 5$ & 0.54 \\
\hline \multicolumn{8}{|l|}{ Role emotional } \\
\hline Baseline & $72 \cdot 5$ & $41 \cdot 4$ & 78.5 & $39 \cdot 2$ & & & \\
\hline Change after 12 months & -2.9 & 43.3 & $7 \cdot 0$ & $41 \cdot 4$ & $-9 \cdot 7$ & $-25 \cdot 5,6 \cdot 1$ & 0.22 \\
\hline \multicolumn{8}{|l|}{ Social functioning } \\
\hline Baseline & 78.5 & $25 \cdot 3$ & 76.9 & $27 \cdot 0$ & & & \\
\hline Change after 12 months & -3.5 & $32 \cdot 8$ & 4.2 & 23.6 & -7.5 & $-17 \cdot 5,2.5$ & 0.14 \\
\hline \multicolumn{8}{|l|}{ Bodily pain } \\
\hline Baseline & $65 \cdot 6$ & 28.9 & $69 \cdot 7$ & $26 \cdot 0$ & & & \\
\hline Change after 12 months & -0.2 & $27 \cdot 3$ & -3.5 & 23.5 & 3.9 & $-5 \cdot 0,12 \cdot 9$ & 0.39 \\
\hline \multicolumn{8}{|l|}{ Vitality } \\
\hline Baseline & 53.0 & $20 \cdot 1$ & $56 \cdot 4$ & $22 \cdot 8$ & & & \\
\hline Change after 12 months & 4.5 & $22 \cdot 4$ & -1.0 & $17 \cdot 3$ & $5 \cdot 0$ & $-2 \cdot 0,12 \cdot 1$ & $0 \cdot 16$ \\
\hline \multicolumn{8}{|l|}{ Mental health } \\
\hline Baseline & $66 \cdot 7$ & $18 \cdot 4$ & $66 \cdot 6$ & $17 \cdot 6$ & & & \\
\hline Change after 12 months & $2 \cdot 6$ & $17 \cdot 1$ & 0.4 & $17 \cdot 5$ & $2 \cdot 1$ & $-4 \cdot 0,8 \cdot 1$ & 0.50 \\
\hline
\end{tabular}

INT, intervention group; CON, control group.

*Data are expressed as mean and SD; or $\beta$ and $95 \% \mathrm{Cl}$.

†Health transition: INT $n$ 63, CON $n$ 65; general health: INT $n 62$, CON $n$ 63; physical functioning: INT $n 61$, CON $n$ 65; role physical: INT $n 60$, CON $n$ 62; role emotional: INT $n$ 57, CON $n$ 62; bodily pain: INT $n 63$, CON $n$ 65; vitality: INT $n$ 62, CON $n$ 65; mental health: INT $n 62$, CON $n 65$.

$\ddagger P$ value for difference between treatment groups in ANCOVA test, adjusted for ethnicity and individuals' mean value of the measurements at baseline and 12 months for the respective variable.

Another limitation is the low number (19\%) of male participants in the MetSLIM study. Other lifestyle intervention studies also report low participation rates among men ${ }^{(4,50)}$. The MetSLIM study focused on individuals of Dutch, Turkish and Moroccan origin. However, we did not succeed in recruiting many participants of Moroccan origin. This could possibly have been because we found especially good contact persons within the Dutch and Turkish communities, for example ethnicity-matched general practitioners and a Turkish research assistant with contacts at the intervention locations. Other researchers have concluded that ethnicity-matched recruiters result in better reach to the target group ${ }^{(51)}$. We will investigate this issue further in the process evaluation of the MetSLIM study (forthcoming).

Finally, the quasi-experimental design could be considered a limitation. However, although randomised controlled trials are highly valued, it is debateable if randomised controlled trials are the appropriate research method to evaluate complex interventions ${ }^{(52)}$. In our case, it was considered that randomisation would not be feasible, and even undesirable. As most persons in our target group are probably unfamiliar with research and randomisation, it could have easily provoked dissatisfaction and non-participation if participants were randomly allocated to intervention and control groups, especially within one community. A selective response could therefore be expected with a randomised controlled trial, which would have threatened the recruitment of the target group and the external validity of the study.

\section{Conclusions}

In conclusion, the current study showed that the adapted SLIM lifestyle intervention targeting low-SES individuals of different ethnic origins is effective in improving waist circumference, total and LDL cholesterol, and quality of life after 12 months. Future research is required to investigate whether further adaptations to the lifestyle intervention may be necessary to enhance its effectiveness among different ethnic minorities and to investigate how men and persons of Moroccan origin can be more successfully reached for this lifestyle intervention.

\section{Acknowledgements}

Acknowledgements: The authors thank all the participants and health-care professionals who were involved in the 
MetSLIM study. Financial support: This work was supported by LekkerLangLeven (cooperation between the Dutch Diabetes Research Foundation, the Dutch Kidney Foundation and the Dutch Heart Foundation; grant number 2009.20.021). LekkerLangLeven had no role in the design, analysis or writing of this article. Conflict of interest: None. Authorship: A.J.B. and D.T. contributed equally to this work. A.J.B. and D.T. designed the evaluation study, collected and processed all data, and drafted the manuscript. E.J.M.F. and M.A.v.B. helped to analyse the data and to revise the manuscript. R.J.R. and A.M. were involved in reviewing and improving the manuscript. All authors were involved in designing the MetSLIM protocol and approved the final manuscript. E.J.M.F. is the guarantor of this work and, as such, had full access to all data in the study and takes responsibility for the integrity of the data and the accuracy of the data analysis. Ethics of buman subject participation: This study was conducted according to the guidelines laid down in the Declaration of Helsinki and all procedures involving human subjects were approved by the Medical Ethical Committee of Wageningen University. Written informed consent was obtained from all subjects. The study was registered at the Netherlands Trial Register as NTR3721.

\section{Supplementary material}

To view supplementary material for this article, please visit https://doi.org/10.1017/S1368980017001458

\section{References}

1. Tuomilehto J, Lindstrom J, Eriksson JG et al. (2001) Prevention of type 2 diabetes mellitus by changes in lifestyle among subjects with impaired glucose tolerance. $N$ Engl J Med 344, 1343-1350.

2. Knowler WC, Barrett-Connor E, Fowler SE et al. (2002) Reduction in the incidence of type 2 diabetes with lifestyle intervention or metformin. N Engl J Med 346, 393-403.

3. Ratner R, Goldberg R, Haffner S et al. (2005) Impact of intensive lifestyle and metformin therapy on cardiovascular disease risk factors in the Diabetes Prevention Program. Diabetes Care 28, 888-894.

4. Johnson M, Jones R, Freeman C et al. (2013) Can diabetes prevention programmes be translated effectively into realworld settings and still deliver improved outcomes? A synthesis of evidence. Diabet Med 30, 3-15.

5. Boltri JM, Davis-Smith YM, Seale JP et al. (2008) Diabetes prevention in a faith-based setting: results of translational research. J Public Health Manag Pract 14, 29-32.

6. Kulzer B, Hermanns N, Gorges D et al. (2009) Prevention of Diabetes Self-Management Program (PREDIAS): effects on weight, metabolic risk factors, and behavioral outcomes. Diabetes Care 32, 1143-1146.

7. Laatikainen T, Dunbar JA, Chapman A et al. (2007) Prevention of type 2 diabetes by lifestyle intervention in an Australian primary health care setting: Greater Green Triangle (GGT) Diabetes Prevention Project. BMC Public Health 7, 249.

8. Mau MK, Keawe'aimoku Kaholokula J, West MR et al. (2010) Translating diabetes prevention into native Hawaiian and Pacific Islander communities: the PILI 'Ohana pilot project. Prog Community Health Partnersh 4, 7-16.
9. Ramachandran A, Snehalatha C, Mary S et al. (2006) The Indian Diabetes Prevention Programme shows that lifestyle modification and metformin prevent type 2 diabetes in Asian Indian subjects with impaired glucose tolerance (IDPP-1). Diabetologia 49, 289-297.

10. Mensink M, Feskens EJ, Saris WH et al. (2003) Study on lifestyle intervention and impaired glucose tolerance Maastricht (SLIM): preliminary results after one year. Int J Obes Relat Metab Disord 27, 377-384.

11. Mensink M, Corpeleijn E, Feskens EJ et al. (2003) Study on lifestyle-intervention and impaired glucose tolerance Maastricht (SLIM): design and screening results. Diabetes Res Clin Pract 61, 49-58.

12. Roumen C, Feskens EJ, Corpeleijn E et al. (2011) Predictors of lifestyle intervention outcome and dropout: the SLIM study. Eur J Clin Nutr 65, 1141-1147.

13. Dalstra JA, Kunst AE, Borrell C et al. (2005) Socioeconomic differences in the prevalence of common chronic diseases: an overview of eight European countries. Int J Epidemiol 34, 316-326.

14. Lakerveld J, IJzelenberg W, van Tulder MW et al. (2008) Motives for (not) participating in a lifestyle intervention trial. BMC Med Res Methodol 8, 17.

15. Chinn DJ, White M, Howel D et al. (2006) Factors associated with non-participation in a physical activity promotion trial. Public Health 120, 309-319.

16. Moroshko I, Brennan L \& O'Brien P (2011) Predictors of dropout in weight loss interventions: a systematic review of the literature. Obes Rev 12, 912-934.

17. Uitewaal PJ, Manna DR, Bruijnzeels MA et al. (2004) Prevalence of type 2 diabetes mellitus, other cardiovascular risk factors, and cardiovascular disease in Turkish and Moroccan immigrants in North West Europe: a systematic review. Prev Med 39, 1068-1076.

18. Ujcic-Voortman JK, Schram MT, Jacobs-van der Bruggen MA et al. (2009) Diabetes prevalence and risk factors among ethnic minorities. Eur J Public Health 19, 511-515.

19. Pagoto SL, Schneider KL, Oleski JL et al. (2012) Male inclusion in randomized controlled trials of lifestyle weight loss interventions. Obesity (Silver Spring) 20, 1234-1239.

20. Uitewaal P, Bruijnzeels M, De Hoop T et al. (2004) Feasibility of diabetes peer education for Turkish type 2 diabetes patients in Dutch general practice. Patient Educ Couns 53, 359-363.

21. Liu JJ, Davidson E, Bhopal RS et al. (2012) Adapting health promotion interventions to meet the needs of ethnic minority groups: mixed-methods evidence synthesis. Health Technol Assess 16, issue 44, 1-469.

22. Bukman AJ, Teuscher D, Feskens EJM et al. (2014) Perceptions on healthy eating, physical activity and lifestyle advice: opportunities for adapting lifestyle interventions to individuals with low socioeconomic status. BMC Public Health 14, 1036.

23. Cleland V \& Ball K (2010) Recruiting hard-to-reach populations: lessons from a study of women living in socioeconomically disadvantaged areas of Victoria, Australia. Health Promot J Aust 21, 243-244.

24. Teuscher D, Bukman AJ, van Baak MA et al. (2015) Challenges of a healthy lifestyle for socially disadvantaged people of Dutch, Moroccan and Turkish origin in the Netherlands: a focus group study. Crit Public Health 25 , 615-626.

25. Teuscher D, Bukman AJ, Meershoek A et al. (2015) Adapting an effective lifestyle intervention towards individuals with low socioeconomic status of different ethnic origins: the design of the MetSLIM study. BMC Public Health 15, 125.

26. Statistics Netherlands (n.d.) Definitions: someone with a Dutch background. http://www.cbs.nl/en-GB/menu/ methoden/begrippen/default.htm?ConceptID $=88$ (accessed March 2016). 
27. Statistics Netherlands (n.d.) Definitions: someone with a foreign background. http://www.cbs.nl/en-GB/menu/methoden/ begrippen/default.htm?ConceptID=37 (accessed March 2016).

28. Health Council of the Netherlands (2006) Guidelines for a Healthy Diet 2006. Report no. 2006/21E. The Hague: Health Council of the Netherlands.

29. Bermúdez RM, García SG, Surribas DP et al. (2011) Consensus Document. Recommendations on assessing proteinuria during the diagnosis and follow-up of chronic kidney disease. Nefrologia 31, 331-345.

30. Friedewald WT, Levy RI \& Fredrickson DS (1972) Estimation of the concentration of low-density lipoprotein cholesterol in plasma, without use of the preparative ultracentrifuge. Clin Chem 18, 499-502.

31. Grundy SM, Cleeman JI, Daniels SR et al. (2005) Diagnosis and management of the metabolic syndrome: an American Heart Association/National Heart, Lung, and Blood Institute scientific statement. Circulation 112, 2735-2752.

32. Wendel-Vos GW, Schuit AJ, Saris WH et al. (2003) Reproducibility and relative validity of the short questionnaire to assess health-enhancing physical activity. J Clin Epidemiol 56, 1163-1169.

33. Dekker LH, Snijder MB, Beukers MH et al. (2011) A prospective cohort study of dietary patterns of non-western migrants in the Netherlands in relation to risk factors for cardiovascular diseases: HELIUS-Dietary Patterns. BMC Public Health 11, 441.

34. RIVM (2013) NEVO-online versie 2013/4.O, Nederlands Voedingsstoffenbestand (Dutch Food Composition Database). Bilthoven: RIVM.

35. van Lee L, Geelen A, Hooft van Huysduynen EJ et al. (2012) The Dutch Healthy Diet index (DHD-index): an instrument to measure adherence to the Dutch Guidelines for a Healthy Diet. Nutr J 11, 49-57.

36. van Lee L, Feskens EJ, Hooft van Huysduynen EJ et al. (2013) The Dutch Healthy Diet index as assessed by $24 \mathrm{~h}$ recalls and FFQ: associations with biomarkers from a crosssectional study. J Nutr Sci $\mathbf{2}$, e40.

37. Ware JE Jr \& Sherbourne CD (1992) The MOS 36-Item ShortForm Health Survey (SF-36). I. Conceptual framework and item selection. Med Care 30, 473-483.

38. Pearson TA, Mensah GA, Alexander RW et al. (2003) Markers of inflammation and cardiovascular disease: application to clinical and public health practice: a statement for healthcare professionals from the Centers for Disease Control and Prevention and the American Heart Association. Circulation 107, 499-511.

39. Ridker PM (2003) Clinical application of C-reactive protein for cardiovascular disease detection and prevention. Circulation 107, 363-369.
40. Willett W (1998) Nutritional Epidemiology, 2nd ed. New York: Oxford University Press.

41. Oldham PD (1962) A note on the analysis of repeated measurements of the same subjects. J Chronic Dis $\mathbf{1 5}$, 969-977.

42. Selvin S (2004) Statistical Analysis of Epidemiologic Data, 3rd edn. New York: Oxford University Press.

43. Ma J, Yank V, Xiao L et al. (2013) Translating the Diabetes Prevention Program lifestyle intervention for weight loss into primary care: a randomized trial. JAMA Intern Med $\mathbf{1 7 3}$, 113-121.

44. Ackermann RT, Finch EA, Brizendine E et al. (2008) Translating the Diabetes Prevention Program into the community: the DEPLOY pilot study. Am J Prev Med 35, $357-363$.

45. Kramer MK, Kriska AM, Venditti EM et al. (2009) Translating the Diabetes Prevention Program: a comprehensive model for prevention training and program delivery. Am J Prev Med 37, 505-511.

46. Blokstra A, Vissink P, Venmans LMAJ et al. (2011). Measuring the Netherlands. A Monitoring Study of Risk Factors in the General Population, 2009-2010. Bilthoven: RIVM.

47. Bohr AD, Laurson K \& McQueen MB (2016) A novel cutoff for the waist-to-height ratio predicting metabolic syndrome in young American adults. BMC Public Health 16, 295.

48. Carroll J, Winters P, Fiscella K et al. (2015) Process evaluation of practice-based diabetes prevention programs: what are the implementation challenges? Diabetes Educ $\mathbf{4 1}$, 271-279.

49. Admiraal WM, Vlaar EM, Nierkens V et al. (2013) Intensive lifestyle intervention in general practice to prevent type 2 diabetes among 18 to 60-year-old South Asians: 1-year effects on the weight status and metabolic profile of participants in a randomized controlled trial. PLOS ONE 8, e68605.

50. Hossain D, Yuginovich T, Lambden J et al. (2015) Impact of Red Apple Healthy Lifestyles Programme on healthy eating behaviour of low socio-economic participants in rural and regional communities in Australia. Int J Health Promot Educ $\mathbf{5 3}, 136-146$.

51. Hartman MA, Nierkens V, Cremer SW et al. (2013) A process evaluation: does recruitment for an exercise program through ethnically specific channels and key figures contribute to its reach and receptivity in ethnic minority mothers? BMC Public Health 13, 768.

52. Bothwell LE, Greene JA, Podolsky SH et al. (2016) Assessing the gold standard - lessons from the history of RCTs. New Eng J Med 374, 2175-2181. 